\title{
Species removal and experimental warming in a subarctic tundra plant community
}

\author{
Christian Rixen · Christa P. H. Mulder
}

Received: 2 March 2008 / Accepted: 30 April 2009 / Published online: 29 May 2009

(C) Springer-Verlag 2009

\begin{abstract}
Neighbor interactions are likely to play an important role in subarctic plant communities. We conducted experiments in Interior Alaska in which we crossed species removal with greenhouse warming manipulations. We examined changes in community biomass, and in plant survival and growth of individual species in response to experimental warming and to: (1) removal of whole species versus an equivalent amount of biomass across many species, and (2) removal of subdominant (locally common) versus minor (locally uncommon) plants. Community biomass indicated compensation in growth after removal of minor species and after biomass removal without elimination of entire species, but under-compensation after removal of subdominants. Growth and survival of individual species showed facilitation between some species. Warming increased growth of dominant vascular plants, but at the same time reduced survival, and these impacts were greater for larger, more mesic species than for the smaller species associated with drier habitats. Growth of mosses was reduced by the warming. Removal effects did not differ
\end{abstract}

Communicated by Mercedes Bustamante.

C. Rixen · C. P. H. Mulder

Institute of Arctic Biology,

University of Alaska Fairbanks,

Fairbanks, AK 99775, USA

C. Rixen $(\bowtie)$

Unit Ecosystem Boundaries, Alpine Ecosystems,

WSL Swiss Federal Institute for Forest,

Snow and Landscape Research, Flüelastrasse 11,

7260 Davos Dorf, Switzerland

e-mail: rixen@slf.ch between warming and ambient conditions. The results indicate that common species are able to reduce resources for others (competitive effect) and increase their growth after neighbor removal, whereas locally uncommon species are not able to respond rapidly to increased resources made available by neighbor removal. Therefore, the impact of the presence of common species on locally uncommon species was facilitative overall, but not vice versa. The balance between disturbances such as changes in temperature and species losses from the community will likely be crucial in determining shifts in subsequent community composition.

Keywords Bryophytes - Competition - Disturbance · Facilitation $\cdot$ Neighbor removal

\section{Introduction}

Positive and negative species interactions are important factors in structuring communities and species composition (Bertness and Callaway 1994; Kitzberger et al. 2000; Bruno et al. 2003; Michalet et al. 2006; Brooker et al. 2008). Plants can positively influence each other in several ways, including through protection from disturbance or herbivory, or through amelioration of harsh conditions (Callaway et al. 2002). Such beneficial effects of neighbors are known from communities in deserts (Wilby and Shachak 2004), salt marshes (Bertness and Hacker 1994; Mulder and Ruess 1998) and arctic and alpine meadows and tundra (Choler et al. 2001; Olofsson 2004), although some studies have failed to identify positive interactions (Moen 1993; Olofsson et al. 1999). It has been hypothesized that under benign conditions negative interactions like competition are predominant, whereas under harsh physical conditions positive interactions become more relevant (Callaway et al. 
2002; Travis et al. 2005). In tundra communities this hypothesis has been supported by neighbor-removal experiments that revealed increasing positive interactions among plants with increasing stress (Callaway et al. 2002; Wipf et al. 2006). However, individual tundra species differ in their responses to neighbor removal, especially to removal of specific groups of neighbors (Del Moral 1983; Jonasson 1992; Hobbie et al. 1999; Bret-Harte et al. 2004). For example, total aboveground biomass of the shrub Ledum palustre increased with removal of other shrubs, and the removal of moss (Sphagnum spp.) increased biomass of the shrub Betula nana (Hobbie et al. 1999) indicating competition, while in similar habitat neighbor removal decreased survival, growth and reproduction of the shrub Empetrum nigrum in winters with little snow cover, pointing to facilitation (Wipf et al. 2006). Plant responses to neighbor removal thus are likely to depend on plant characteristics (e.g., whether plants are vascular or non-vascular, woody or herbaceous; Callaway 1998; Hobbie et al. 1999; Choler et al. 2001; Bret-Harte et al. 2004). But a second possible explanation for contradictory results of species-removal experiments is that the effects of removal of biomass per se are often confounded with effects of removal of specific species or groups of species. In almost all plant communities, a few species comprise most of the biomass while a much larger number of species occur at low abundance (e.g., Ugland and Gray 1982; Wilson et al. 1996; Weiher and Keddy 1999). Species' reactions to neighbor removal may depend on whether the species removed and the species remaining are dominant (common) or minor (uncommon) in the community, because dominant and minor species are likely to differ in their interspecific interactions. By definition, dominant species are highly abundant and thrive in that particular environment; they are likely to excel at reducing resources (Aarssen 1983), and compete primarily with conspecifics or other dominant species. Minor species may be species that are reduced in abundance due to competition with dominants, or they may be species that are naturally abundant elsewhere but for which this environment is sub-optimal, or species whose growth form or life history characteristics are such that they never represent a high proportion of the total biomass. In the latter two cases, minor species may be limited in their ability to respond to reduced competition from dominants (Aksenova et al. 1998; Mulder et al. 2004). For example, Aksenova et al. (1998) showed that dominant tundra species increased their number of shoots after removal of presumed competitors, whereas subordinate species responded negatively to the removal of dominants. Thus, we might predict that in harsh environments the effects of common species on minor species will be primarily facilitative, and that the removal of the dominants will have negative impacts under harsh conditions (removal of facilitation) and more neutral effects under benign conditions (where facilitation is less important). In contrast, dominant plants may benefit from removal of minor species under both harsh and less harsh conditions.

The effects of warmer temperatures on tundra vegetation have been addressed in numerous studies (e.g., Arft et al. 1999; van Wijk et al. 2004; Hollister et al. 2005); however, vegetation responses differ greatly between different regions of the Arctic (van Wijk et al. 2004), community types, and plant species (Hollister et al. 2005). How warmer temperatures affect plant interactions may depend on whether the environment becomes more or less stressful for plants as well as on plant growth form. Although some studies have shown no consistent responses to elevated temperatures by growth form (Chapin et al. 1995; Hollister et al. 2005), others indicate that plant responses might depend on whether they are evergreen or deciduous, with deciduous species showing stronger warming responses (Arft et al. 1999; Kudo et al. 1999). Furthermore, warmer sites that contain species with higher growth rates may produce stronger growth responses to elevated temperature than colder sites with species that are less productive but more tolerant of harsh environmental conditions (Arft et al. 1999).

In this study we investigate how subarctic tundra communities recover from biomass removal. We evaluated changes in community biomass, and in plant survival and growth of individual species in response to: (1) removal of whole species versus an equivalent amount of biomass across many species, and (2) removal of subdominant (locally common) versus minor (locally uncommon) plants. We then evaluated whether the response of individual species to removal treatments was robust or sensitive to specific environmental conditions by comparing responses under ambient conditions with those under a perturbation regime (greenhouses with a large increase in temperature). Specifically, we tested the following hypotheses:

1) Species removal will result in lower community biomass and have a stronger impact on the remaining plants than the removal of an equivalent amount of biomass without the entire removal of some species.

2) Responses of plants to species removal will depend both on the dominance status (dominant or minor) of the responding species and the dominance status of the species removed, with dominant species showing more positive responses to removal of minor species than vice versa.

3) Species' responses to the removal treatments will be more negative under more stressful conditions, and this difference will be greater for minor than for dominant species. The warmer conditions are likely to be considered stressful because of a large increase in 
temperature; however, some species may benefit from the warming.

\section{Materials and methods}

Study site and plant communities

The species-removal experiment was carried out in subarctic tundra at Twelve Mile Summit, $60 \mathrm{~km}$ north of Fairbanks, Alaska, USA $\left(65^{\circ} 23^{\prime} \mathrm{N}, 145^{\circ} 58^{\prime} \mathrm{W}\right)$ from July 2002 to June 2004. The plant communities of the study site are dominated by dwarf shrubs such as Vaccinium uliginosum L., long-lived vascular species such as Cassiope tetragona (L.) D. Don, Dryas octopetala L. and Loiseleuria procumbens (L.) Desv., mosses, and lichens (Table 1). Other less frequently present functional groups are grasses and herbs. Dominant plant species consisted of four vascular species, three moss species, and lichens; vascular and non-vascular plants were similar in total abundance. The four dominant vascular plants are characterized as follows: Cassiope tetragona (Ericaceae, white arctic mountain heather) is a medium-sized evergreen plant commonly found in tundra with long-lasting snow cover. Vaccinium uliginosum (Ericaceae, blueberry), is a relatively large deciduous shrub (up to $40 \mathrm{~cm}$ ) dominant or co-dominant in moderately moist dwarf shrub types, bogs or muskegs (Viereck and Little 1986). Dryas octopetala (Rosaceae, alpine dryad) is a winter-green shrub (see Molau and Molgaard 1996) that occurs in gravelly and rocky barrens, as well as on alpine ridges, particularly in dry sites. Loiseleuria procumbens (Ericaceae, alpine azalea) is a low evergreen woody plant occasional to common in dry stony heath on acid, dry bouldery slopes. The three dominant bryophyte species can be characterized as follows: Hylocomium splendens (Hedw.) B.S.G., a feather moss growing in large patches in boreal understorey and tundra vegetation, Rhytidium rugosum (Hedw.) Kindb., a mat-forming pleurocarpous species from rocky slopes, and Polytrichum juniperinum Hedw., an acrocarpous star moss from dry tundra vegetation (nomenclature follows Anderson et al. 1990).

Our study plots were located along an elevational and moisture gradient, and species composition shifted along this gradient. Lower-lying, moister communities were dominated by dwarf shrubs (V. uliginosum and C. tetragona) and the three mentioned moss species. The higher communities with harsher environmental conditions such as drought or high winds were dominated by $D$. octopetala, L. procumbens and lichens. The communities always had almost $100 \%$ plant cover and consisted of four to 11 vascular plant species and one to four moss species plus lichens.
Study design and experimental treatments

We selected 18 experimental sites along the moisture elevation gradient (Table 1). The experiment was originally designed to test the effects of changes in species richness across a moisture gradient; however, it quickly became obvious that the moisture gradient was difficult to define and the species richness changes could not be maintained. Instead, the more interesting results were driven by dominance status and taxonomic (byrophyte vs. vascular) status of the species examined. Sites were more or less evenly distributed across a total area of approximately $1 \mathrm{~km}^{2}$. Because the terrain consisted of rolling hills, sites with different communities were spatially interspersed. Each site comprised one replicate of a full factorial experiment with two levels of environmental conditions (greenhouse and ambient) and three levels of removal treatment. Each site consisted of six circular plots, $40 \mathrm{~cm}$ in diameter. We trenched the margins of the plots with a knife to cut roots and rhizomes and restrict resource allocation from ramets outside the plot to ramets inside. The trenching did not have any visible detrimental effects on plants inside the plot. Plots were in two groupings of three plots placed in a row, 0.3-1 $\mathrm{m}$ apart-far apart enough to be independent of each other and close enough to be as similar in species composition as possible and to fit under one greenhouse. One group received the greenhouse treatment (see below) and one was left under control conditions. The greenhouse and ambient plots were so close together that the plots within each grouping were not more similar than between groupings. Each group of three plots consisted of a species-removal (SR) plot, a biomass-removal (BRd) plot with removal of parts of the two most dominant species and a control (C) plot without any removal. The inclusion of a biomassremoval treatment in the experimental design allowed us to distinguish between effects due to removal of a species or set of species (SR vs. BRd plots) and effects due simply to biomass removal (BRd vs. C) (Diaz et al. 2000). This design resulted in a total plot number of $n=108$.

Removal treatments were carried out between 20 July and 14 August 2002 in a random order with respect to the community type. At most sites dominant plants consisted of one vascular and one non-vascular species (Table 1). Dominant species were represented by the four vascular plant species and the three moss species described above, plus lichens (Table 1). All other species were considerably less abundant and considered minor. All plots within a site received the same treatment (i.e., removal of the same species; Table 1). The SR treatment was as follows: the most abundant species (representing $50-80 \%$ of total cover) was left in the plot because removing it would have resulted in such high biomass reduction that the BRd treatment would have been difficult to complete without removing entire 


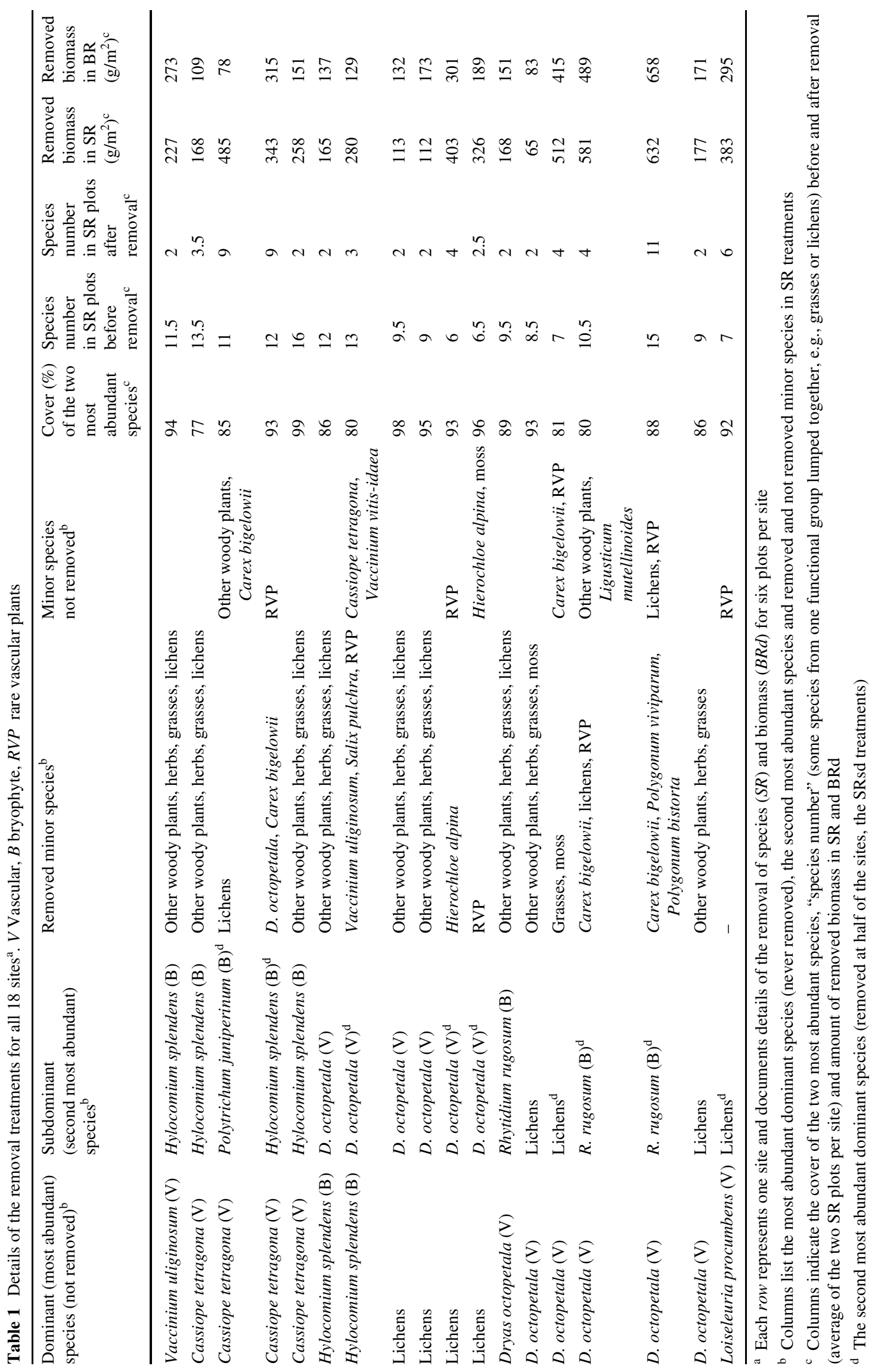


species. On half of all SR plots (SRsd), the remaining subdominant species (representing $20-40 \%$ of cover) and half of the minor species (1-10\% of cover) were removed in order to reduce species richness by more than one species. Species to be removed were selected at random from each dominance category, and where there was an odd number of minor species the number to be removed was rounded down. On the remaining SR plots (SRm) dominants were not touched but all minor species were removed. Thus, we had two categories of species removal: removal including a locally subdominant species (SRsd) and removal of only the minor (locally uncommon) species (SRm).

All lichens were treated as one unit in the plant removal, and so were all grasses (Poaceae) and any species that did not occur in all six plots per site (rare vascular plants; Table 1). For example, the second to last site in Table 1 received the SRm treatment (as well as the BRd and C treatments), and we removed all seven minor species from the species-removal plots: woody plants, herbs and grass. Vascular plants were removed by uprooting as carefully as possible to minimize soil disturbance. Only above-ground biomass was considered in the removal analysis because below-ground removal would have resulted in an unacceptable soil disturbance. Mosses and lichens could easily be pulled out of the ground. The removed biomass was dried at $65^{\circ} \mathrm{C}$ for $48 \mathrm{~h}$, sorted by species and weighed.

The BRd plots were set up to control for the effects of removing biomass (as opposed to entire species) from plots. Within each trio we tried to remove an equivalent amount of fresh biomass from the BRd plot as from the SR plot (methodological limitations see below), but in such a way that no species was completely eliminated. This generally required the removal of biomass from the two most abundant species (entire ramets). For example, at the second to last site in Table 1, the SR treatment resulted in the removal of $177 \mathrm{gm}^{-2}$, while on the matching biomassremoval plots we removed $171 \mathrm{gm}^{-2}$ of the dominant $D$. octopetala and the dominant lichens. Minor species were not removed from the BR plots because their abundance was usually too low. The $\mathrm{C}$ plots were left untouched. Thus, comparing the $\mathrm{C}$ plots with the BR plots allows us to evaluate the effect of biomass removal per se. Although we attempted to remove the same amount of biomass in the BR as in the SR treatments (see Table 1), this was difficult to achieve because the removed amount had to be estimated from the fresh biomass that contained woody plant material as well as wet bryophytes that can retain up to 20 times their own weight in water (Clymo and Hayward 1982). This issue was accounted for in the statistical analysis (see below).

For the greenhouse treatment, plastic greenhouses were set up to cover one of the two groups of plots per site. The dimensions of the greenhouses were $80 \times 200-330 \mathrm{~cm}$, depending on the size of the plot group. The A-frame greenhouses were constructed with PVC pipe and eight-mil (0.2-mm) vinyl sheeting. We left the greenhouses at the sites during one whole growing season from spring snowmelt on 24 April (2/3 of the sites were snow-free by then) up to and including 14 September 2003.

Temperatures at the soil surface were recorded at each site (under greenhouse and ambient conditions) with miniature temperature loggers (iButton thermochron) and UTL loggers (miniature universal temperature loggers; Krummenacher et al. 1998). Precipitation in the area was measured with a pluviometer located within the study area. Soil moisture of the plots was recorded using a Delta-T HH2 and ML2 sensor (Delta-T Devices, Cambridge, UK) on 12 September 2003, which was 2 days after a rainfall of $2 \mathrm{~mm}$.

The mean temperature at the soil surface during the growing season (measured from 17 June to 7 September 2003) was increased by $4.5^{\circ} \mathrm{C}$ in the greenhouses $\left(13.5^{\circ} \mathrm{C}\right.$ vs. $9^{\circ} \mathrm{C}$ for ambient temperature plots). The mean maximum temperature during that time period was $12^{\circ} \mathrm{C}$ higher in greenhouses $\left(42^{\circ} \mathrm{C}\right.$ vs. $\left.30^{\circ} \mathrm{C}\right)$. Precipitation outside of the greenhouses during that time period was $246 \mathrm{~mm}$, whereas there was no precipitation on the greenhouse plots. Despite the lack of precipitation under the greenhouses, mean soil moisture was not affected (10.5\% under greenhouses versus $10.7 \%$ in ambient plots, $\left.F_{(1,34)}=0.45, P>0.8\right)$, probably due to lateral water flow. The removal treatment did not change soil moisture in 2003 or $2004(P>0.3$ in both years). The experimental warming with greenhouses was likely confounded with environmental factors such as relative humidity, wind speed etc. Plant responses to the greenhouse treatments should therefore be interpreted as perturbation due to several factors and not only increased temperatures.

\section{Biomass, module size, and survival}

Above-ground biomass was harvested on two circular areas per plot, each $11.5 \mathrm{~cm}$ in diameter, at peak biomass at the end of June 2004. We limited the harvest to these areas in order to retain the option of measuring biomass the following year. One area was randomly chosen in one quarter of the circle, the other was located in the opposite quadrant. Vascular plants were clipped at the surface and mosses and lichens were pulled out of the ground. The biomass was dried at $65^{\circ} \mathrm{C}$ for $48 \mathrm{~h}$, sorted by species and weighed. Different responses may be found for different response variables (Goldberg et al. 1999). Therefore, we also measured leaf or shoot length of individual common species before and after the treatments. Five individual ramets/ fronds of each species per plot (all common vascular plants plus the bryophytes Hylocomium splendens and Rhytidium rugosum) were labeled with colored wire (D. octopetala 
and $L$. procumbens at the base of the ramet, C. tetragona and $V$. uliginosum on the lead branch a few centimeters from tip) and measured from the wire to the tip of the shoot. As all investigated species show clonal growth, individual ramets were selected randomly but at a maximum distance from each other so as to minimize interactions between potentially connected ramets. We measured the following: shoot length of $C$. tetragona, $V$. uliginosum and $L$. procumbens, leaf length of $D$. octopetala (as shoot length of this species is difficult to measure due to its morphology; Molau and Molgaard 1996), and frond length of the feather mosses Hylocomium splendens and Rhytidium rugosum (moss growth was measured in a total of 39 plots). The measurements were carried out immediately after the removal treatment in July/August 2002 and repeated in August 2003 and June 2004

\section{Statistical analysis}

Data were analyzed in SPSS 15.0 (SPSS 2006). Explanatory variables in the ANOVA included Site as a random blocking factor, Identity of vascular plant species dominating the plot, Removal type (SRsd, SRm, BRd or control) and Greenhouse as fixed factors. Amount of removed biomass had to be included in the analysis as a covariate for comparison of SRsd, SRm and BRd because the removed biomass in the SR and the BRd treatments was often not equal, and we would expect higher biomass removal to lead to larger impacts in plant growth (Table 2; Fig. 1). The following contrasts were included in the analysis: removals versus control (no removal), BRd versus SR and SRsd versus SRm. This approach enabled us to test separately for differences between removal and no removal, biomass removal and species removal, and removal of common and uncommon species by using the entire power of the statistical model. Two- and three-way interactions were included according to the statistical model shown in Table 2. To test whether the slopes of relationships between standing biomass and amount of removed biomass were different from zero, we applied univariate linear regression.

We analyzed standing biomass for the entire aboveground community. We also compared the standing biomass of dominant and minor species, and of vascular versus non-vascular plants between treatments. However, biomass of the most abundant species was not included in the biomass of the dominant species because we expected an experimental artifact resulting in a negative relationship between biomass removed in SRsd treatments (which did not include the most abundant species) and standing biomass (the more biomass in the most abundant species, the less biomass in the remaining dominant species). Growth of the labeled individual ramets was analyzed as change in shoot or leaf length of vascular plants and frond length of bryophytes between 2002 and 2003 (mean values per plot). In order to scale the growth responses, we additionally report percent increase or decrease from the mean [instead of indices such as RNE and RCI (Grace 1995; Oksanen et al. 2006) that increased the number of missing values where calculations were based on zero values]. For module length, variables of all four dominant vascular plants were included in one analysis. Similarly the frond lengths of the two bryophyte species were analyzed in one analysis. Furthermore, we analyzed the change between 2002 and 2004 to test whether impacts were still discernible a year after the greenhouse treatment had ceased. Survival of vascular plants was calculated as the percentage of live labeled ramets per plot. On six plots all five labeled vascular plant ramets died which reduced the number of replicates for the variable module growth. No observable mortality occurred in bryophytes, and it was therefore not analyzed. Some species that were removed were able to regrow from plant fragments left in the ground. The distribution of residuals was normal and homoscedastic $(P>0.05)$ and therefore transformations to meet assumptions of ANOVA were not necessary. Results are reported as significant at $\alpha=0.05$ and as marginally significant at $\alpha=0.10$. Data are reported as mean $\pm 1 \mathrm{SE}$.

\section{Results}

\section{Biomass}

The removal treatments resulted in an initial biomass loss of $236.1( \pm 158.6) \mathrm{gm}^{-2}$ for BR, $161.4( \pm 74.6) \mathrm{gm}^{-2}$ for $\mathrm{SRm}$ and $438.5( \pm .4) \mathrm{gm}^{-2}$ for SRsd (Fig. 1). After 2 years (2002-2004), new growth had fully compensated for the biomass removed in two treatments (SRm and BRd), as shown by the comparison of total standing biomass to biomass removed (Fig. 1; details of statistical results for biomass, survival and growth are reported in Table 2). The overall mean of standing biomass decreased by $118 \mathrm{gm}^{-2}$ in all removal treatments compared with the control $\left[849 \pm 332\right.$ (SE) vs. $\left.967 \pm 330 \mathrm{gm}^{-2}\right]$. Standing biomass was similar at sites where only minor species were removed between removal (SRm) and control plots $\left(959 \pm 336 \mathrm{gm}^{-2}\right.$ vs. $980 \pm 313 \mathrm{gm}^{-2}$, LSD n.s. $)$ but lower for removal plots at SRsd sites $\left(715 \pm 367 \mathrm{gm}^{-2}\right.$ vs. $954 \pm 354 \mathrm{gm}^{-2}$, LSD $\left.P<0.01\right)$. However, since biomass removed differed between the three removal treatments, a better way to evaluate differences in productivity is to examine whether standing biomass differs across treatments for a given level of biomass removed. The slopes of the relationships between removed and standing biomass differed by treatment [interaction of removed biomass with removal type: $F_{(2,63)}=8.43, P<0.001$; Fig. 2 ]: for SRm it 
Table 2 ANOVA table for standing above-ground biomass, survival and shoot/leaf growth. For other abbreviations, see Table 1

\begin{tabular}{|c|c|c|c|c|c|c|c|c|c|}
\hline \multirow[t]{2}{*}{ Sources of variation } & \multicolumn{3}{|c|}{ Biomass $\left(\mathrm{g} / \mathrm{m}^{2}\right)$} & \multicolumn{3}{|c|}{ Survival (\%) } & \multicolumn{3}{|c|}{ Module size (mm) } \\
\hline & $d f$ & MS & $F$ & $d f$ & MS & $F$ & $d f$ & MS & $F$ \\
\hline Common vasc. plant identity ${ }^{\mathrm{a}}$ & 3 & 976,495 & $29.130 * * *$ & 3 & 0.470 & $9.29 * * *$ & 3 & 459.2 & $62.51 * * *$ \\
\hline Site & 14 & 352,802 & $10.524 * * *$ & 14 & 0.128 & $2.54 * *$ & 14 & 17.0 & $2.32 *$ \\
\hline Greenhouse & 1 & 32,344 & 0.965 & 1 & 3.630 & $71.81 * * *$ & 1 & 61.9 & $8.42 * *$ \\
\hline Removed biomass $^{\mathrm{b}}$ & 1 & 544,952 & $16.256 * * *$ & 1 & 0.033 & 0.65 & 1 & 14.1 & 1.91 \\
\hline Removal type ${ }^{c}$ & 3 & 30,725 & 0.917 & 3 & 0.126 & $2.49+$ & 3 & 12.6 & 1.72 \\
\hline Contrast removal versus no removal & 1 & 758 & 0.023 & 1 & 0.006 & 0.11 & 1 & 0.1 & 0.01 \\
\hline Contrast BRd versus SR & 1 & 670 & 0.020 & 1 & 0.012 & 0.25 & 1 & 36.1 & $4.92 *$ \\
\hline Contrast SRm versus SRsd & 1 & 90,747 & 2.707 & 1 & 0.360 & $7.12 * *$ & 1 & 1.7 & 0.23 \\
\hline Removal type $\times$ Removed biomass & 2 & 282,736 & $8.434 * * *$ & 2 & 0.189 & $3.75^{*}$ & 2 & 16.5 & 2.25 \\
\hline Contrast BRd versus $\mathrm{SR} \times$ Removed biomass & 1 & 275,048 & $8.205 * *$ & 1 & 0.249 & $4.92 *$ & 1 & 6.2 & 0.84 \\
\hline Contrast SRm versus SRsd $\times$ Removed biomass & 1 & 290,425 & $8.664 * *$ & 1 & 0.130 & 2.57 & 1 & 26.8 & $3.65+$ \\
\hline Removal type $\times$ Greenhouse & 3 & 11,855 & 0.354 & 3 & 0.039 & 0.77 & 3 & 8.7 & 1.18 \\
\hline Contrast removal versus no removal $\times$ Greenhouse & 1 & 1,421 & 0.042 & 1 & 0.010 & 0.21 & 1 & 3.5 & 0.48 \\
\hline Contrast BRd versus $\mathrm{SR} \times$ Greenhouse & 1 & 290 & 0.009 & 1 & 0.014 & 0.27 & 1 & 12.8 & 1.74 \\
\hline Contrast SRm versus SRsd $\times$ Greenhouse & 1 & 33,853 & 1.010 & 1 & 0.092 & 1.82 & 1 & 9.7 & 1.33 \\
\hline Greenhouse $\times$ Common vasc. plant identity & 3 & 49,871 & 1.488 & 3 & 0.136 & $2.70+$ & 3 & 182.4 & $24.84 * * *$ \\
\hline Removal type $\times$ Common vasc. plant identity & 7 & 25,523 & 0.761 & 7 & 0.048 & 0.95 & 7 & 21.5 & $2.93 *$ \\
\hline $\begin{array}{l}\text { Contrast removal versus no removal } \times \\
\text { Common vasc. plant identity }\end{array}$ & 3 & 18,512 & 0.552 & 3 & 0.064 & 1.26 & 3 & 49.0 & $6.67 * * *$ \\
\hline $\begin{array}{l}\text { Contrast BRd versus } \mathrm{SR} \times \text { Common vasc. } \\
\text { plant identity }\end{array}$ & 3 & 40,997 & 1.223 & 3 & 0.038 & 0.75 & 3 & 1.0 & 0.13 \\
\hline $\begin{array}{l}\text { Contrast } \mathrm{SRm} \text { versus SRsd } \times \text { Common vasc. } \\
\text { plant identity }\end{array}$ & 1 & 137 & 0.004 & 1 & 0.031 & 0.62 & 1 & 0.8 & 0.11 \\
\hline $\begin{array}{l}\text { Removal type } \times \text { Greenhouse } \times \text { Common vasc } \\
\text { plant identity }\end{array}$ & 7 & 54,903 & 1.638 & 7 & 0.102 & $2.02+$ & 4 & 7.1 & 0.97 \\
\hline $\begin{array}{l}\text { Contrast removal versus no removal } \times \\
\text { Greenhouse } \times \text { Com. vasc. plant }\end{array}$ & 3 & 14,013 & 0.418 & 3 & 0.153 & $3.04 *$ & 2 & 11.2 & 1.53 \\
\hline $\begin{array}{l}\text { Contrast BRd versus } \mathrm{SR} \times \text { Greenhouse } \times \\
\text { Com. vasc. plant }\end{array}$ & 3 & 33,918 & 1.012 & 3 & 0.056 & 1.11 & 2 & 3.0 & 0.41 \\
\hline $\begin{array}{l}\text { Contrast SRm versus SRsd } \times \text { Greenhouse } \times \\
\text { Common vasc. plant identity }\end{array}$ & 1 & 240,527 & $7.175 * *$ & 1 & 0.086 & 1.69 & & & \\
\hline Error & 63 & 33,522 & & 63 & 0.051 & & 57 & 7.3 & \\
\hline Total & 108 & & & 108 & & & 99 & & \\
\hline
\end{tabular}

$+P<0.1, * P<0.05, * * P<0.01, * * * P<0.001$

a The common vascular (vasc.) plant species in that community (indication of community type)

b Amount of removed biomass in grams

c Type of removal treatment

was positive (2.63) and significantly different from zero $(P<0.05)$, for SRsd it was negative $(-1.44)$ and significantly different from zero $(P<0.05)$, and for BRd it was not different from zero (0.03). These values indicate compensation or overcompensation after removal of minor species, exact compensation after equivalent biomass removal, and under-compensation after removal of dominants. These responses were driven by the remaining species which had not been removed and not by regrowth of removed species: there was no positive or negative relationship between regrowth of removed species and removed biomass within each treatment [interaction of removed biomass with removal type: $F_{(2,63)}=0.44, P>0.6$; all slopes $<0.3$, $P>0.39$ ], but the relationships between standing biomass of the remaining unremoved species and removed biomass showed almost exactly the same pattern as those presented in Fig. 2 [interaction of removed biomass with removal type: $F_{(2,63)}=7.33, P<0.001$; slope $\mathrm{SRm}=2.32, P<0.05$; slope $\quad \mathrm{SRsd}=-1.63, \quad P=0.002 ; \quad$ slope $\quad \mathrm{BRd}=0.01$, $P>0.95]$. 


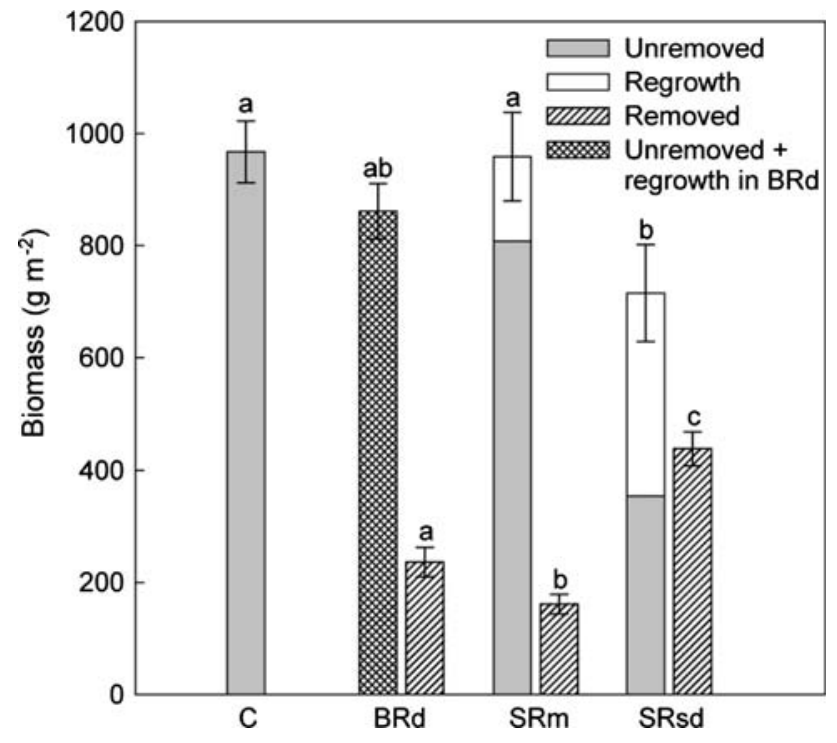

Fig. 1 Not removed, regrown (both in 2004) and removed biomass in the control $(C)$, biomass removal $(B R d)$, removal of minor species $(S R m)$ and removal of common subdominant species ( $S R s d)$ treatments. BRd could not be separated in not removed and regrown biomass because species were not removed entirely. Different letters indicate significant differences between treatments in post hoc LSD tests

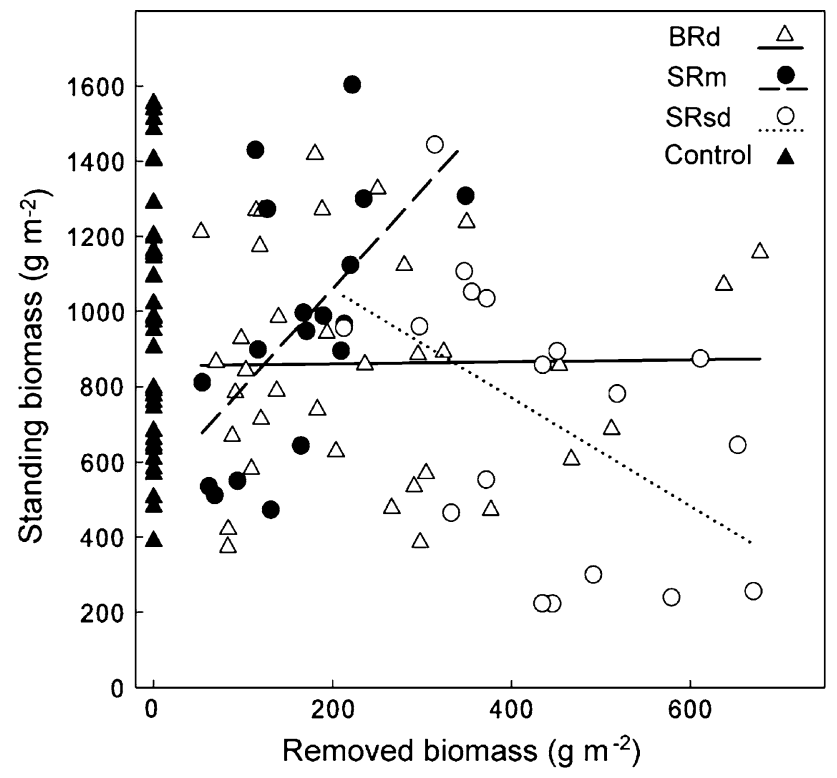

Fig. 2 Influence of amount of removed biomass on standing aboveground growth of entire communities. Regression lines of SR treatments are significantly different from BRd (removal of parts of common dominant species) (significant interaction Removed biomass $\times$ Contrast SR vs. BR; Table 2), and those of SRm are significantly different from SRsd (significant interaction Removed biomass $\times$ Contrast SRm vs. SRsd; Table 2). Regression lines are different from zero as follows: BR, $R^{2}<0.01, P>0.9$; SRm, $R^{2}=0.34, P=0.01$; SRsd, $R^{2}=0.26$, $P=0.03$. For abbreviations, see Fig. 1

The removal treatments influenced plants in different dominance groups in different ways. The standing biomass of the subdominant species (excluding the most abundant, i.e., those species subjected to removal in the SRsd treatments) was significantly increased by the removal of minor species $[\mathrm{SRm}$ vs. SRsd $\times$ removed biomass for subdominant species only: $F_{(1,63)}=5.17, P<0.026$; Fig. 3a]. The slope of the relationship between biomass of subdominant species and total removed biomass in SRm plots was positive (2.33) and marginally different from zero $(P=0.062)$, while those for BR and SRsd plots were not different from zero (both $P>0.4$ ). Regrowth of removed minor species was not significantly different from zero $(P=0.19)$; therefore, growth after removal of minor species was driven by the remaining subdominant species. The biomass of minor species was not significantly altered by the removal treatments [interaction removed biomass $\times$ removal type: $F_{(2,63)}=1.86, P=0.17$; Fig. 3b]. Testing vascular versus non-vascular plants revealed that biomass of both groups tended to be increased by the removal of minor species [non-vascular plants, SRm vs. SRsd $\times$ removed biomass: $F_{(1,63)}=3.44, P=0.073$; Fig. 3c,d]. Only vascular plants increased in biomass after the BR treatment [slope significantly different from zero $P=0.007$, BRd vs. SR $\times$ removed biomass: $F_{(1,63)}=9.29, P=0.003$ ].

The removal effect did not differ between plots with different identities of the most common vascular plant (Table 2 , common vascular plant identity $\times$ removal type) or between greenhouse treatments (Table 2, greenhouse $\times$ removal type) nor was the three-way interaction between greenhouse, removal type, and common vascular plant identity significant.

\section{Survival}

Overall mortality of the common vascular plant species was higher under greenhouse conditions $\left[F_{(1,63)}=71.81\right.$, $P<0.001$; Fig. 4a; Table 2]: survival was $92 \%$ under ambient conditions but only 55\% under greenhouses. Survival under greenhouses differed slightly between communities with different common vascular plant identities [interaction abundant vascular plant identity $\times$ greenhouse: $F_{(3,63)}=$ 2.70, $P=0.053]$. C. tetragona showed the lowest survival under greenhouses compared with ambient conditions ( $32 \%$ vs. $92 \%$ ) followed by V. uliginosum (27\% vs. $60 \%$ outside of greenhouses), D. octopetala (66\% vs. $96 \%)$ and L. procumbens ( $47 \%$ vs. $73 \%$ ).

The type of removal affected the survival of the common vascular plants (marginally significant; Table 2). In particular, SRm significantly reduced survival compared with SRsd [62\% vs. $85 \%$; Fig. 5, Table 2; contrast SRm vs. SRsd: $\left.F_{(1,63)}=7.12, P=0.01\right]$. Removing an equivalent amount of biomass was less detrimental than removing whole species [Table 2; interaction contrast BRd vs. $\mathrm{SR} \times$ removed biomass $\left.F_{(1,63)}=4.92, P=0.03\right]$. There were no significant interactions between removal treatments and 


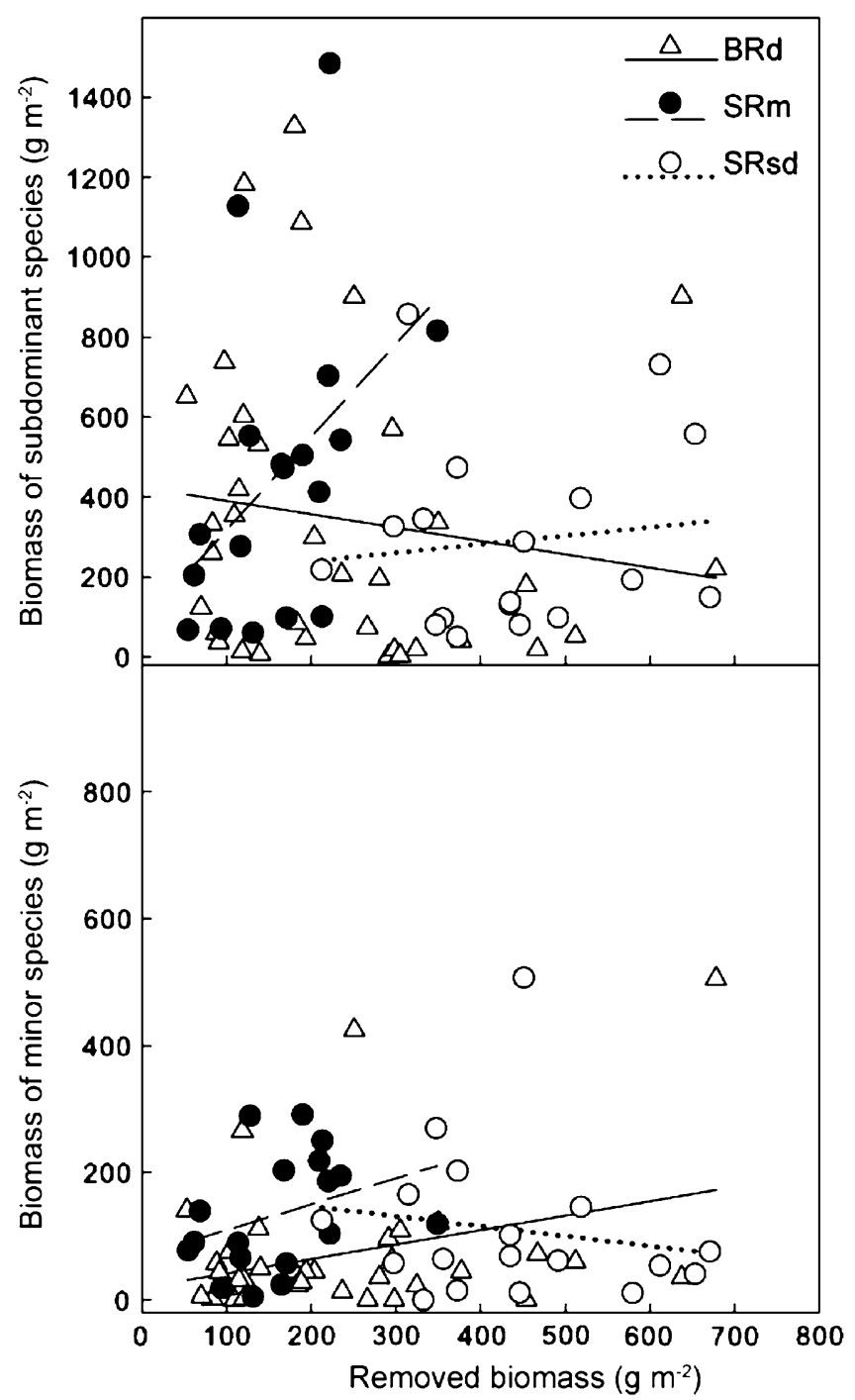

Fig. 3 Influence of amount of removed biomass on standing aboveground growth of dominant species versus minor species and vascular versus non-vascular species. Note the different scales on the $y$-axes. Significances of regression lines are as follows. Dominant species: interaction contrast SRm vs. SRsd $\times$ Removed biomass $F_{(1,63)}=5.17$, $P<0.026$. SRm regression line was marginally significantly different

greenhouse treatment, or between removal treatments and common vascular plant identity.

Module size measurements

The overall reaction of vascular plants to the warming was an increase in growth of individual modules, that is, they produced longer leaves and/or shoots under the greenhouses $\left[F_{(1,57)}=8.42, P=0.005\right.$; Fig. 3b; Table 2]. The reaction to the greenhouse treatment differed significantly between communities with different common vascular plant identities [interaction greenhouse $\times$ common vascular plant identity: $F_{(1,57)}=24.84, P<0.001$; Table 2]: $V$. uliginosum showed the largest difference between plants in the

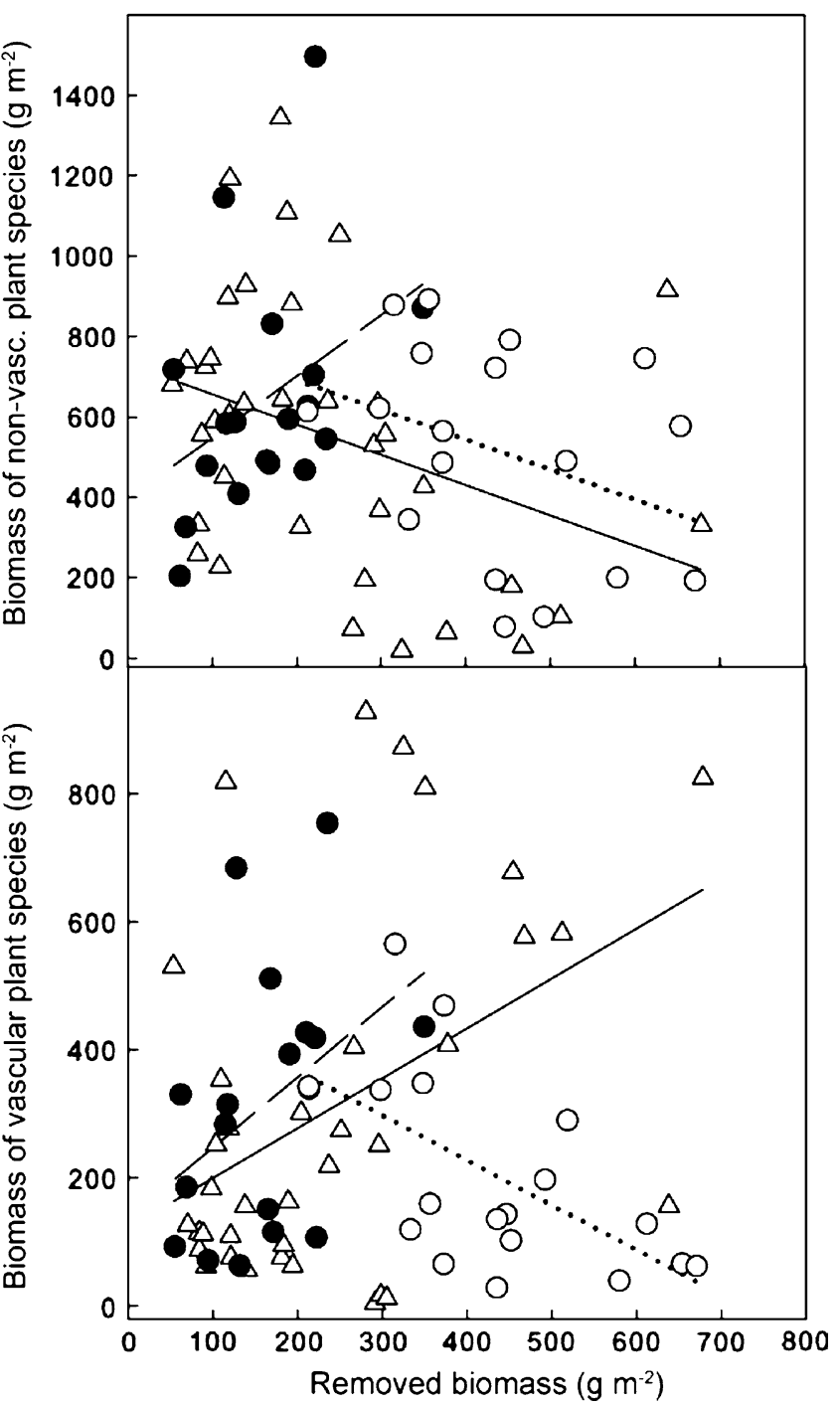

from zero $(P=0.062)$. Minor species: all interactions $P>0.1$. Non-vascular plant species: interaction contrast SRm versus SRd $x$ Removed biomass $F_{(1,63)}=3.44, P=0.073$. Vascular plant species: all interactions $P>0.1$. Note the different scale of the $x$-axes of a and $\mathbf{c}$ versus $\mathbf{b}$ and $\mathbf{d}$. For abbreviations, see Fig. 1

greenhouse and in the open followed by $C$. tetragona (both $P<0.05$ in a post hoc test; Fig. $4 b$ ). The module size of neither D. octopetala nor $L$. procumbens showed a significant response to the greenhouse treatment $(P>0.05$ in post hoc test). Scaling the growth responses by analyzing the percent increase or decrease from the mean resulted in the same order of plant species. In contrast to the vascular plants, the module size of moss was reduced considerably under the greenhouses [both species combined $F_{(1,17)}=26.57$, $P<0.001]$.

Species removal reduced the leaf or shoot length increment (as measured by the difference between length after 1 year and the initial year, and after 2 years and the initial year) of the vascular plant species in the SR treatments 


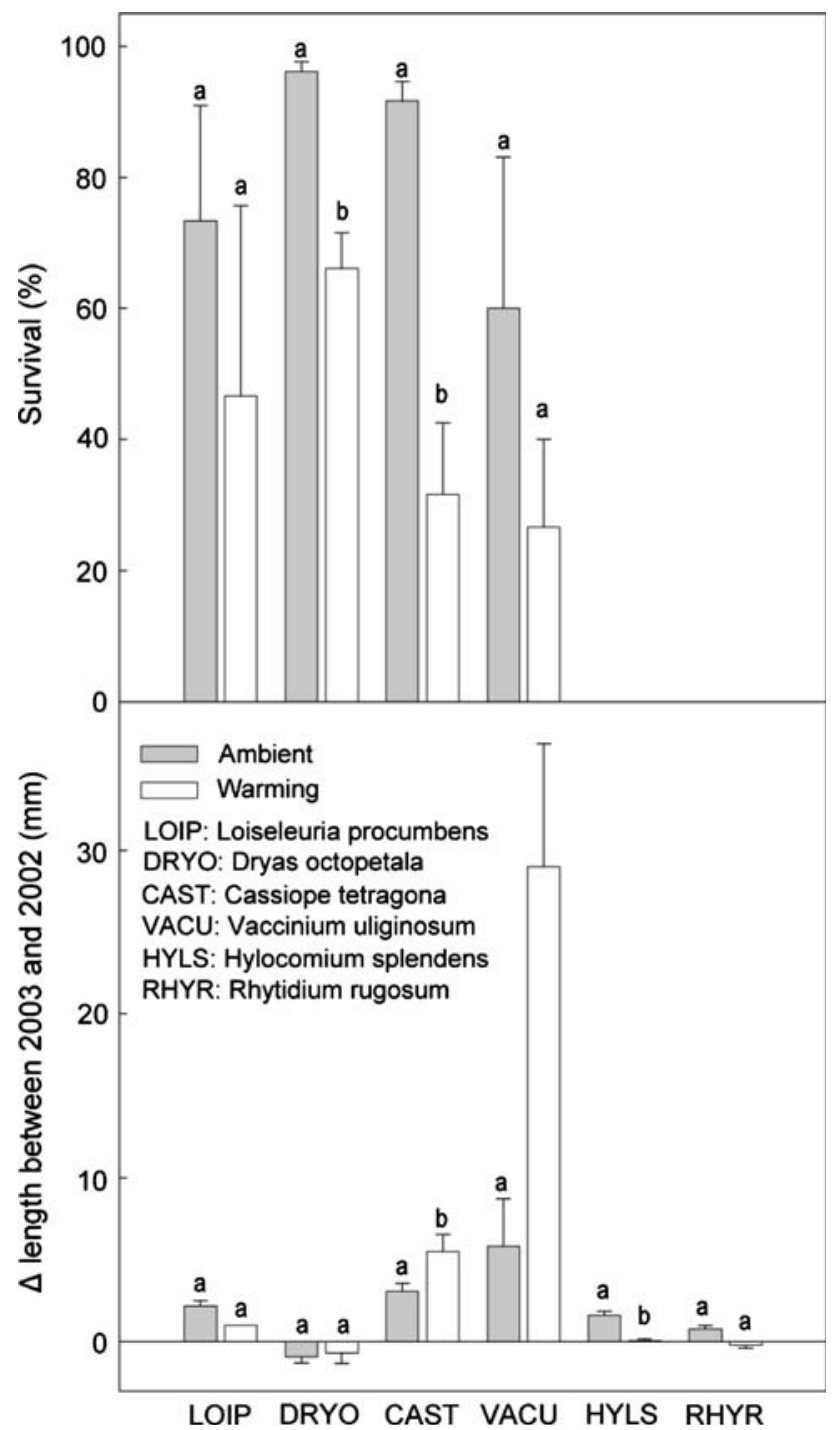

Fig. 4 Survival and module growth (as the difference between 2003 and 2002) of the common vascular plant species Loiseleuria procumbens, Dryas octopetala, Cassiope tetragona and Vaccinium uliginosum under ambient and greenhouse conditions. Different letters indicate significant differences in post hoc LSD tests between greenhouse and ambient conditions separately for each species

compared with the BR treatments [2003: contrast BRd vs. SR: $F_{(1,57)}=4.92, P=0.031$; Table 2; Fig. 6]. In 2004, this effect was even stronger $\left[F_{(1,49)}=6.22, P=0.016\right]$. However, module size in SRm plots was not significantly different from that in SRsd plots in either year. The degree to which plant module size responded to the removal treatments depended on the common vascular plant identity (interaction common vascular plant identity $\times$ removal type, $P=0.011$; interaction common vascular species $\times$ contrast removal vs. no removal, $P<0.001$; Table 2; Fig. 6 ; however, post hoc tests between the common vascular plants were n.s.). Module size of $V$. uliginosum and C. tetragona was reduced by SRm treatments (and to a

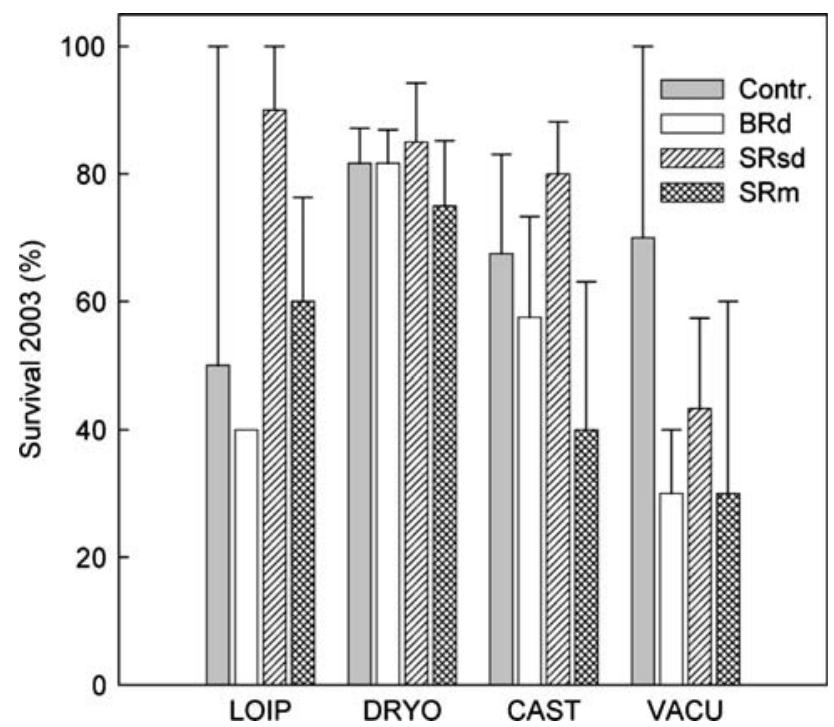

Fig. 5 Survival of ramets (percentage of live labeled ramets per plot) of the four common vascular plant species in 2003 under the different removal treatments. Across all species, the SRsd and the SRm treatment are significantly different in post hoc LSD tests. For abbreviations, see Figs. 1 and 4

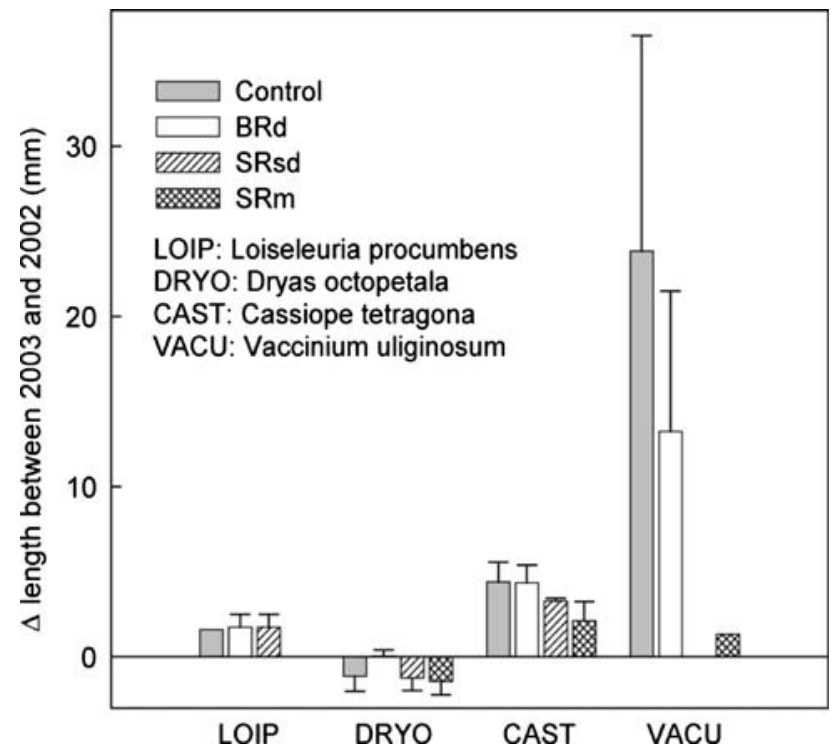

Fig. 6 Difference in shoot/leaf length between 2003 and 2002 for each common vascular plant species $L$. procumbens, D. octopetala, C. tetragona and $V$. uliginosum (including sites where species was only subdominant) in response to removal treatments. The interaction Common vascular plant identity $\times$ Removal type $(P=0.011)$ and the interaction Common vascular species $\times$ Contrast removal versus no removal $(P<0.001)$ were significant, but not the LSD post hoc tests

lesser extent by SRd treatments). Module size of D. octopetala was slightly decreased in growth by SRm, almost unaffected by SRsd and increased by BR. Module size of Loiseleuria decumbens was not affected by removal treatments. The analysis of percent increase or decrease from the mean resulted in the same pattern of removal effects on 
module growth of the four species. The interactions between the removal and greenhouse treatments were not significant. Growth of moss fronds was not influenced by the removal treatments (all removal contrasts $P>0.1$ ).

\section{Discussion}

This study demonstrates: (1) how species removal had a greater influence on a plant community than the removal of an equivalent amount of biomass, (2) that responses to species removal differed between dominant and minor species and whether dominant or minor species were removed, (3) that warming resulted in enhanced growth of vascular plants but also in higher mortality of shoots, and (4) that growth of mosses was decreased by the warming treatment.

Biomass changes following removal treatments: dominant versus minor species

For these tundra communities the effect of removal of entire species was stronger than that of removal of an equivalent amount of biomass: standing biomass was not affected by the BR treatment, and survival and module size in BRd treatments were not different from those in control plots (with the exception of survival of $D$. octopetala). Furthermore, responses to BR treatments did not differ between dominance groups of the responding plants: both dominant and minor groups exhibited exact compensation in response to biomass removal without species removal. In contrast, biomass, survival and module size were affected by the species-removal treatments. As predicted, growth responses in SR treatments depended both on whether dominant or minor species were removed, and on the status of the responding plant. First, communities showed compensatory growth following biomass removal when minor species were removed, and regressions of standing biomass against biomass of minor species removed actually suggest overcompensation. In contrast, biomass removal of dominant species resulted in under-compensation in biomass. In several other studies in arctic tundra, most species did not respond with compensatory growth to neighbor removal (Jonasson 1992; Shevtsova et al. 1997; Hobbie et al. 1999; Bret-Harte et al. 2004, but see Gerdol et al. 2002). BretHarte et al. (2004) argued that vascular tundra plants may have such rigid niche complementarity that they are unable to utilize the available space or resources (at least in the short-term). An examination of the dominance status of the response plants in our study, however, showed that not all species were able to respond to biomass removal. Dominant plants showed compensation after removal of minor species, suggesting release from interspecific competition and the ability to use the newly available space or resources. In contrast, minor plants did not show compensation after removal of dominant (and minor) species. These results suggest that the impacts of dominant species on minor species are either very small, or that the combination of facilitation and competition result in a net neutral effect. Our results support the view of Mulder et al. (2004) that minor species may have little ability to increase productivity in the absence of common species and of Smith and Knapp (2003) that dominant species can maintain a high biomass production in the absence of rare and uncommon species. These opposing impacts of neighbor removal on dominant versus minor species may explain why responses to neighbor removal are not consistent, ranging from positive (Sammul et al. 2000; Gerdol et al. 2002), to neutral (BretHarte et al. 2004; Totland et al. 2004), to negative (Shevtsova et al. 1997; Aksenova et al. 1998). In general, our results support our first two hypotheses: removing species has much greater impacts than removing an equivalent amount of biomass, and dominant species are more able to respond to this treatment than minor species.

Differences between vascular plants and bryophytes in response to removal experiments

The analysis of biomass of vascular versus non-vascular plants revealed that both groups were able to compensate for the removal of minor species, which supports the view of Steel et al. (2004) that mechanisms maintaining community structure do not differ fundamentally between vascular plants and bryophytes. On the other hand, vascular plants compensated for biomass removal more than non-vascular plants. Mosses were probably able to compete against the minor species. In fact, dense mats of mosses may prevent other species from establishing (Zamfir 2000; Morgan 2006). On the other hand, mosses are poor competitors for light due to their small size and may not be able to fill gaps as fast as some dominant vascular plants. Other studies on bryophytes have stressed their large role in boreal and arctic ecosystems. For example, turnover rates of bryophytes in Scandinavian boreal forests were very high (Okland and Okland 1996) leading to net primary productivity similar to shrubs (Nilsson and Wardle 2005). However, the role of bryophytes in responding to disturbance in the arctic is not well understood (but see Rydgren et al. 1998; Bret-Harte et al. 2004). Considering how poorly mosses performed in our warming treatment (see discussion below), the fate of bryophytes may be highly relevant to arctic vegetation in a warmer climate.

Changes in survival and module size following removal treatments

The responses of marked individuals of common vascular plants to removal treatments differ from the biomass 
results: survival was reduced by the removal of minor species (but not dominant species or biomass removal), while module size (leaf or shoot length) was reduced by both species-removal treatments. The effects on survival were not different between communities with different common vascular plant identities, suggesting that the presence of minor species may increase survival of existing ramets (a facilitative effect), even though their removal also provides space that is quickly colonized by some of the dominant species (as evidenced by the greater biomass following minor plant removal). In contrast, the changes in shoot or leaf length were strongly species specific: the larger species (the evergreen $C$. tetragona and the deciduous $V$. uliginosum) showed marked reductions in shoot growth while the smaller species (the evergreen $L$. decumbens and the semievergreen $D$. octopetala) species changed very little. It is unlikely that the response of $D$. octopetala was low just because leaf instead of shoot length was measured, as differences in leaf sizes between individual plants were large, hence potentially enabling large growth responses. The pattern of the four species matches that for the responses to the greenhouse treatments (see below). The mechanisms through which some plants facilitate the growth of others are not known for this experiment. However, in harsh climates neighbors may ameliorate growing conditions, e.g., by preventing temperature extremes (Choler et al. 2001), wind or drought (Callaway 1995). For instance, plants in an arctic climate may be better sheltered from wind-blown snow if they are protected by surrounding vegetation (Tranquillini 1980). Even smaller plants can provide protective shelter for larger plants such as the small bryophyte Racomitrium lanuginosum for the larger sedge Carex bigelowii (Carlsson and Callaghan 1991). This may explain why in our experiment larger plant species are facilitated by minor plants. The differences in our study between results on biomass and those on module sizes and survival highlight the need for different variables to determine plant fitness (Goldberg et al. 1999; Tielborger and Kadmon 2000).

Effects of the greenhouse treatment

Community standing biomass tended to be lower under greenhouses, although not significantly so. The lack of a strong negative or positive effect on biomass may be the result of two opposing effects: more benign conditions possibly including reduced wind speed or increased temperatures (which may be beneficial, although the ability of tundra plants to increase maximum photosynthetic rate at higher temperatures may be limited; see Körner 2003), and reduced humidity, which may increase water stress. For instance, changes in survival and module size were in opposite directions, at least for vascular plants: survival generally decreased, while module size generally increased under greenhouse conditions. Although the survival of all species was lower under greenhouses, the magnitude of the impacts differed and responses were the opposite of the growth responses: $V$. uliginosum and $C$. tetragona exhibited the greatest decrease in survival under greenhouses compared with ambient conditions, followed by $L$. procumbens and D. octopetala. Again, stress tolerance may help explain these responses: the faster growing and/or deciduous species may also be more susceptible to drought stress. These different responses in terms of survival and module growth between species resulted in no overall differences between species. Also the responses in module size differed between the smaller species and the larger species: the small species had decreased (L. procumbens) or neutral (D. octopetala) leaf and shoot size under greenhouses, whereas the taller species (C. tetragona and V. uliginosum) showed an increase in shoot size. These species-specific responses may be related to habitat type: the first two species are adapted to fairly dry environments, while the latter two are species generally found in wetter habitats (Hultén 1968; Viereck and Little 1986). The growth rates of the evergreen species from harsher environments are generally lower, and their ability to respond to warmer conditions may be limited by their physiology (Körner 2003). Unlike for the vascular plant species, shoot length of the two dominant moss species was negatively impacted by the greenhouse conditions. This negative impact of dry conditions on moss growth is consistent with previous studies: experiments have found that bryophytes (excluding Sphagnum spp.) were either not affected or decreased in growth by warming (Hobbie et al. 1999).

Interactions between greenhouse treatments and biomass-removal experiments

Several studies in tundra and alpine meadow communities have shown that under harsher environmental conditions facilitative effects outweighed negative interactions (Choler et al. 2001; Callaway et al. 2002), and this leads to our hypothesis that any facilitative effects should be greater under greenhouse conditions. We did not find differences in responses to neighbor removal between ambient and greenhouse conditions. However, given the opposing impacts on survival and module size, and the resulting lack of differences in total biomass, we could not designate either the ambient or the greenhouse environment as the more stressful one.

\section{Conclusion}

This study found support for the first two hypotheses: that impacts of species removal are much greater than those of 
the removal of an equivalent amount of biomass, and that the responses of plants to species removal will depend both on the dominance status (dominant or minor) of the responding species and the dominance status of the species removed. The net impact of the presence of dominant species on biomass of minor species was positive, but the reverse was not true. However, the presence of minor species did have positive effects on the survival and module size of the dominant vascular plants, suggesting that although minor species reduce the growth of new ramets, they may also improve conditions for existing ramets. Species' responses to the removal treatments were not different under greenhouse treatments. Probably, warmer temperatures are not necessarily less stressful when humidity decreases at the same time, which exerts stress on some species. Responses of vascular plants and bryophytes to removal did not differ consistently; however, the negative impacts of increased temperatures on bryophyte growth (found in this study as well as others) suggest that compensatory responses may be limited under continued change. Furthermore, among the dominant vascular plant species those most tolerant of the conditions under greenhouses were also those least capable of showing compensatory growth in response to species removal. Thus we conclude that under current conditions tundra plants in this habitat are capable of rapid biomass compensation (at the community level) following species loss, but that their continued ability to respond in a compensatory fashion under an altered environmental regime is less certain.

Acknowledgments We are grateful to Sonja Wipf, Tumi Traustason and Jamie Hollingsworth for help with field work. The study was supported by a post-doctoral fellowship [81ZH-068470] from the Swiss National Science Foundation and the Swiss Academy of Sciences. The experiments comply with the current laws of the country in which they were performed.

\section{References}

Aarssen LW (1983) Ecological combining ability and competitive combining ability in plants - toward a general evolutionary theory of coexistence in systems of competition. Am Nat 122:707-731

Aksenova AA, Onipchenko VG, Blinnikov MS (1998) Plant interactions in alpine tundra: 13 years of experimental removal of dominant species. Ecoscience 5:258-270

Anderson LE, Crum HA, Buck WR (1990) List of the mosses of NorthAmerica north of Mexico. Bryologist 93:448-499

Arft AM et al (1999) Response patterns of tundra plant species to experimental warming: a meta-analysis of the International Tundra Experiment. Ecol Monogr 69:491-511

Bertness MD, Callaway R (1994) Positive interactions in communities. Trends Ecol Evol 9:191-193

Bertness MD, Hacker S (1994) Physical stress and positive associations among marsh plants. Am Nat 144:363-372

Bret-Harte MS et al (2004) Plant and soil responses to neighbour removal and fertilization in Alaskan tussock tundra. J Ecol 92:635-647
Brooker RW et al (2008) Facilitation in plant communities: the past, the present, and the future. J Ecol 96:18-34

Bruno JF, Stachowicz JJ, Bertness MD (2003) Inclusion of facilitation into ecological theory. Trends Ecol Evol 18:119-125

Callaway RM (1995) Positive interactions among plants. Bot Rev 61:306-349

Callaway RM (1998) Are positive interactions species-specific? Oikos 82:202-207

Callaway RM et al (2002) Positive interactions among alpine plants increase with stress. Nature 417:844-848

Carlsson BA, Callaghan TV (1991) Positive plant interactions in tundra vegetation and the importance of shelter. J Ecol 79:973-983

Chapin FS, Shaver GR, Giblin AE, Nadelhoffer KJ, Laundre JA (1995) Responses of arctic tundra to experimental and observed changes in climate. Ecology 76:694-711

Choler P, Michalet R, Callaway RM (2001) Facilitation and competition on gradients in alpine plant communities. Ecology 82:32953308

Clymo RS, Hayward PM (1982) The ecology of Sphagnum. In: Smith AJE (ed) Bryophyte ecology. Chapman and Hall, London, pp 229-290

Del Moral R (1983) Competition as a control mechanism in subalpine meadows. Am J Bot 70:232-245

Diaz S et al (2000) Practical guidelines for removal experiments. In: GCTE/LTER Launch Workshop, GCTE network of removal experiments on the role of biodiversity in ecosystem functioning, pp $1-8$

Gerdol R, Brancaleoni L, Marchesini R, Bragazza L (2002) Nutrient and carbon relations in subalpine dwarf shrubs after neighbour removal or fertilization in northern Italy. Oecologia 130:476-483

Goldberg DE, Rajaniemi T, Gurevitch J, Stewart-Oaten A (1999) Empirical approaches to quantifying interaction intensity: competition and facilitation along productivity gradients. Ecology 80:1118-1131

Grace JB (1995) On the measurement of plant competition intensity. Ecology 76:305-308

Hobbie SE, Shevtsova A, Chapin FS (1999) Plant responses to species removal and experimental warming in Alaskan tussock tundra. Oikos 84:417-434

Hollister RD, Webber PJ, Bay C (2005) Plant response to temperature in Northern Alaska: Implications for predicting vegetation change. Ecology 86:1562-1570

Hultén E (1968) Flora of Alaska and neighboring territories: a manual of the vascular plants. Arctic Inst of North America, Washigton, DC

Jonasson S (1992) Plant responses to fertilization and species removal in tundra related to community structure and clonality. Oikos 63:420-429

Kitzberger T, Steinaker DF, Veblen TT (2000) Effects of climatic variability on facilitation of tree establishment in northern Patagonia. Ecology 81:1914-1924

Körner C (2003) Alpine plant life, 2nd edn. Springer, Berlin

Krummenacher B, Budmider K, Mihajlovic D, Blank B (1998) Periglaziale Prozesse und Formen im Furggentälti, Gemmipass. Mitt Eidgenössisch Inst Schnee- und Lawinenforsch Davos 56:1-245

Kudo G, Nordenhall U, Molau U (1999) Effects of snowmelt timing on leaf traits, leaf production, and shoot growth of alpine plants: comparisons along a snowmelt gradient in northern Sweden. Ecoscience 6:439-450

Michalet R et al (2006) Do biotic interactions shape both sides of the humped-back model of species richness in plant communities? Ecol Lett 9:767-773

Moen J (1993) Positive versus negative interactions in a high alpine block field - germination of Oxyria digyna seeds in a Ranunculus glacialis community. Arctic Alp Res 25:201-206

Molau U, Molgaard P (1996) ITEX manual. Danish Polar Center, Copenhagen 
Morgan JW (2006) Bryophyte mats inhibit germination of non-native species in burnt temperate native grassland remnants. Biol Invasions 8:159-168

Mulder CPH, Ruess RW (1998) Effects of herbivory on arrowgrass: interactions between geese, neighboring plants, and abiotic factors. Ecol Monogr 68:275-293

Mulder CPH, Bazeley-White E, Dimitrakopoulos PG, Hector A, Scherer-Lorenzen M, Schmid B (2004) Species evenness and productivity in experimental plant communities. Oikos 107:50 63

Nilsson MC, Wardle DA (2005) Understory vegetation as a forest ecosystem driver: evidence from the northern Swedish boreal forest. Frontiers Ecol 3:421-428

Okland RH, Okland T (1996) Population biology of the clonal moss Hylocomium splendens in Norwegian boreal spruce forests. II. Effects of density. J Ecol 84:63-69

Oksanen L, Sammul M, Magi M (2006) On the indices of plant-plant competition and their pitfalls. Oikos 112:149-155

Olofsson J (2004) Positive and negative plant-plant interactions in two contrasting arctic-alpine plant communities. Arctic Antarct Alp Res 36:464-467

Olofsson J, Moen J, Oksanen L (1999) On the balance between positive and negative plant interactions in harsh environments. Oikos 86:539-543

Rydgren K, Hestmark G, Okland RH (1998) Revegetation following experimental disturbance in a boreal old-growth Picea abies forest. J Veg Sci 9:763-776

Sammul M, Kull K, Oksanen L, Veromann P (2000) Competition intensity and its importance: results of field experiments with Anthoxanthum odoratum. Oecologia 125:18-25

Shevtsova A, Haukioja E, Ojala A (1997) Growth response of subarctic dwarf shrubs, Empetrum nigrum and Vaccinium vitis-idaea, to manipulated environmental conditions and species removal. Oikos 78:440-458

Smith MD, Knapp AK (2003) Dominant species maintain ecosystem function with non-random species loss. Ecol Lett 6:509-517

SPSS (2006) SPSS for Windows, 15.0th edn. SPSS, Chicago
Steel JB, Wilson JB, Anderson BJ, Lodge RHE, Tangney RS (2004) Are bryophyte communities different from higher-plant communities? Abundance relations. Oikos 104:479-486

Tielborger K, Kadmon R (2000) Temporal environmental variation tips the balance between facilitation and interference in desert plants. Ecology 81:1544-1553

Totland O, Grytnes JA, Heegaard E (2004) Willow canopies and plant community structure along an alpine environmental gradient. Arctic Antarct Alp Res 36:428-435

Tranquillini W (1980) Winter desiccation as the cause for alpine timberline. In: Benecke U, Davis R (eds) Mountain environments and subalpine tree growth. Forest Research Institute, New Zealand Forest Service, Wellington, pp 263-267

Travis JMJ, Brooker RW, Dytham C (2005) The interplay of positive and negative interactions across an environmental gradient: insights from an individual-based simulation model. Biol Lett 1:5-8

Ugland K, Gray JS (1982) Lognormal distributions and the concept of community equilibrium. Oikos 39:171-178

van Wijk MT et al (2004) Long-term ecosystem level experiments at Toolik Lake, Alaska, and at Abisko, Northern Sweden: generalizations and differences in ecosystem and plant type responses to global change. Global Change Biol 10:105-123

Viereck LA, Little EL (1986) Alaska trees and shrubs. University of Alaska Press, Fairbanks

Weiher E, Keddy PA (1999) Relative abundance and evenness patterns along diversity and biomass gradients. Oikos 87:355-361

Wilby A, Shachak M (2004) Shrubs, granivores and annual plant community stability in an arid ecosystem. Oikos 106:209-216

Wilson JB et al (1996) Are there assembly rules for plant species abundance? An investigation in relation to soil resources and successional trends. J Ecol 84:527-538

Wipf S, Rixen C, Mulder CPH (2006) Advanced snowmelt causes shift towards positive neighbour interactions in a subarctic tundra community. Global Change Biol 12:1496-1506

Zamfir M (2000) Effects of bryophytes and lichens on seedling emergence of alvar plants: evidence from greenhouse experiments. Oikos 88:603-611 